\title{
J.A. Naudé
}

\section{STYLISTIC VARIATION IN THREE ENGLISH TRANSLATIONS OF THE DEAD SEA SCROLLS}

\section{ABSTRACT}

Since the discovery of the Dead Sea Scrolls in 1947 different English translations were published. In this article the stylistic variation of three of these translations are analysed. It is suggested that the issue of stylistic variation boils down to linguistically inscribed preference in the choice and construction of discourses in the translated texts, i.e. a case of identifying the norms governing the patterning of translational behaviour within a given socio-cultural milieu. Vermes' translation demonstrates the tendency to simplify the language used in translation. In the translation by Wise, Abegg \& Cook there is an overall tendency to spell things out rather than leave them implicit. The translation of García Martínez demonstrates the trend towards general textual conventionality as opposed to textual creativity as in the case of the translation of Wise, Abegg \& Cook and Vermes.

\section{INTRODUCTION}

Since the discovery of the Dead Sea Scrolls in 1947, different English translations were published. When one compares these translations, many differences can be seen. The research problem of this article is as follows: Why do the various English translations differ? A description and an explanation offered for such differences will be offered. The hypothesis is that these differences boil down to the stylistic variations of the translators of the Dead Sea Scrolls.

The main part of the article consists of a partial analysis of a sub-corpus of three of these English translations within the systemic model proposed by Munday (2002). The following versions are included in the analysis: The Complete Dead Sea Scrolls in English by Geza Vermes $(1997,2004)$ and its predecessor The Dead Sea Scrolls in English (1962, 1975, 1987 and 1995); The Dead Sea Scrolls Translated. The Qumran Texts in English by Florentino García Martínez $(1994,1996)$ and The Dead Sea Scrolls. A New Translation by Michael Wise, Martin Abegg and Edward Cook (1996).

Prof. J. A. Naudé, Department of Afroasiatic Studies, Sign Language and Language Practice, University of the Free State, P.O. Box 339, Bloemfontein, 9300, South Africa. E-mail: naudej.hum@ufs.ac.za. 
In this article the regularities and recurrent patterns present in certain translations but omitted in others are pointed out, i.e. specifically the stylistic variation of the translators. A recurrent lexical phrase may be a favourite expression/quirk of the translator - independent of the style of the author. Translators are writers, and like other writers may have their particular favoured expressions. "Style" is defined here in the sense of a translator's characteristic use of language, his or her individual profile of linguistic habits, in comparison to other translators. In this sense, style is not a question of creativity (or lack thereof), but rather a question of preferred choices (cf. Kenny 2000, who focuses on the issue of creativity). The issue of stylistic variation boils thus down to linguistically inscribed preference in the choice and construction of discourses in the translated texts, i.e. a case of identifying the norms governing the patterning of translational behaviour within a given socio-cultural milieu. According to Sidiropoulou (2004:8), linguistic preference may be assumed to relate to:

- grammatical preference in message construction,

- assumptions prevalent in the culture-specific way a target language conceptualises universal notions,

- gender-sensitive assumptions that affect discourse construction in intercultural communication,

- assumptions about culturally effective persuasion strategies in a target environment,

- assumptions about some culturally appropriate discourse style relative to such cognitive notions as audience participation and involvement, etc.

Preference is reflected in target discourses and is assumed to constitute part of a target linguistic identity. Baker (2004:35) summarises some of these features:

- Specific syntactic features such as modality, deixis, etc.;

- Lexis (archaic vs. informal vs. slang);

- Preference for fixed, recurrent phraseology;

- Preference for specific turns of phrase;

- Preference for specific phrases that realise a translation strategy, such as glossing/explicitation;

- Use of gender-conscious language;

- Choice of texts/themes;

- Use of paratexts (e.g., forewords, footnotes and glossaries).

The analysis is based on the corpus of Bible translations and religious literature, which is in the process of being established at the University of the Free State, Bloemfontein, South Africa. The compilation principles as well as the nature and scope of this corpus are discussed elsewhere (e.g., Naudé 2004). 


\section{A SYSTEMIC MODEL FOR THE ANALYSIS}

To deal adequately with large amounts of texts, Munday (2002:78) recently started to develop a new descriptive approach. The target text is located within its own cultural system to determine its role and reception in its own system. According to this system, a profile of the target text is produced. By following this method, translation strategies are identified and an attempt is made to gain some understanding of their impact on the cultural level. The actual implementation of this model brings together the following ideas and tools, each of which contains the following particularly relevant attributes and uses:

- Preliminary data: Information on title page, meta-texts, and the general strategy.

- Macro-level: The division of the text, titles, and presentation of the chapters, the internal narrative structure, and any overt authorial comment.

- Micro-level: The identification of shifts on different linguistic levels, including the lexical level, grammatical patterns, narrative, point of view, and modality. Logistically, the detailed analysis of long texts poses a problem, which can easily be overcome by making use of corpus linguistics tools. The analytical process is considerably speeded up and far more reliable, which frees the researcher to concentrate on close analysis of the phenomena within the linguistic context of the study.

Corpus-based research in translation studies initially focused on similarities and differences between translated and non-translated text, in an attempt to demonstrate that translations form a distinctive textual system within any target culture. The initial impetus for building and investigating corpora of translated text then was to identify patterns, which are specific to translated text in general (whatever the languages involved). The assumption was that the translation process itself is sufficiently different from regular processes of communication to make it highly likely for the resulting language output to be different from the language produced without the constraint of a fully articulated source text in another language. As corpora began to be compiled, it became necessary to set more specific and local agendas - without losing sight of the initial broader agenda. For example, it has begun necessary to focus on specific languages and to restrict the claims concerning translation-specific patterns to these languages, while at the same time indicating that the broad picture and tendencies we were looking at might prove typical of translations in other languages but was likely to be realised through very different linguistic patterns. In this regard, English translations tend to favour the use of the that connective in reported speech, compared to non-translated English text (Burnett 1999; Olohan \& Baker 2000). The pattern itself is very language-specific and cannot be investigated across languages in order to support a broader claim about the language of translation. Apart from these general and local patterns which involved 
claims about such features as explicitation or simplification and the way these broad tendencies may be realised in local, language-specific patterns, there is also the question of individual variation within a corpus of translated text. Therefore, more recently, researchers have begun to turn their attention to the question of individual variation within a particular corpus of translations.

To determine stylistic variation the preliminary data and macro-structure of the three English translations of the Dead Sea Scrolls indicated above will be described in Section 3. Section 4 provides a corpus-based analysis of the micro-structure of six translated texts of each English translation.

\section{THE PRELIMINARY DATA AND MACRO- STRUCTURE ANALYSIS OF THREE ENGLISH TRANSLATIONS OF THE DEAD SEA SCROLLS}

\subsection{Geza Vermes's The Complete Dead Sea Scrolls in English $(1997,2004)$}

\subsubsection{Preliminary data}

This one-volume translation of the Qumran texts marked the $50^{\text {th }}$ anniversary year of the discovery of the Qumran scrolls and is the fifth edition of The Dead Sea Scrolls in English (1962, 1975, 1987, and 1995). A revised edition was published in 2004 in the Penguin Classics Library. Published accounts indicate that the earlier incarnations of Vermes' book sold over 300000 copies worldwide. The 1962 edition established itself as the leading translation of Qumran texts in English, quickly superseding Theodor Gaster's The Scriptures of the Dead Sea Sect in English translation (1957). The first version (1962) held between its covers just 255 pages, the 2004 edition 694 pages. The fourth edition contained 336 pages. The number of pages of Qumran texts, then, in the complete edition were nearly $40 \%$ longer than in the fourth edition. Though dubbed "complete", it does not mean that each manuscript retrieved from the caves was included. According to Vermes, it is complete in one sense: it offers in a readable form all the texts sufficiently well preserved to be understandable in English, i.e. meaningless scraps or badly damaged manuscript sections are not inflicted on the reader ( $p$. xiii). In other words, the reader will find all that is meaningful and interesting in the non-biblical Qumran texts. He included 212 texts, i.e. $65 \%$ of the text of his nearest contender, the translation of Wise et al. (1996). His goal in this volume is to disclose the message of these ancient manuscripts about ancient Judaism and to a lesser extent about early Christianity ( $p$. xiii). 
The translator is the Hungarian-born Geza Vermes. He is at present Professor Emeritus of Jewish Studies and Emeritus Fellow of Wolfson College, but continues to teach at the Oriental Institute in Oxford. In his autobiography, Providential accidents, he stated that his late wife, Pamela, edited his renderings from the source texts. This would refer only to the earlier editions, because she died in 1993 (p. 146). In a 90-page introduction, he briefly summarises the 50-year history of scrolls research. He presents an overview of the sectarian community associated with the scrolls (which he identifies as the Essenes), its history, and its beliefs:

1. The manuscripts are to be dated from the third century BCE to the latter half of the first century $\mathrm{CE}$, with the vast majority produced in the first century BCE.

2. There is a definite connection between the manuscripts found in Cave 1-11 and the one-time inhabitants of the nearby ruins of Khirbet Qumran.

3. The inhabitants of this site of two centuries, from the latter half of the second century, BCE were the Essenes, the collectors and sometimes the scribes/authors of the scrolls. Vermes argues the case for a single religious movement with two branches: one in a desert retreat at Qumran and one in towns throughout the land.

4. Vermes does not feel the need to defend the weaker points of his construct (his suggestion of Hasidic roots for the Qumran sect continues to trouble many researchers) or to deal with more recent conclusions (L. Schiffman's suggestion of a Sadducean connection is not examined).

There are improvements to the introductory essays. Vermes added references to new Qumran texts that were not included in the fourth edition. He also added references to texts that he mentioned in the fourth edition without full identification. For example, in the fourth edition he referred to "the Messianic Anthology or Testimonia" (p. 29); in the fifth, he adds in parentheses 4Q175 (p. 55). He has included as well updated footnotes (e.g., pp. 6 n. 15, $16 ; 63$ n.1) and discussions (e.g., of 4Q266 and 270 on p. 40). Vermes has added, moreover, two new subheadings to his introduction, both of which incorporate material from the fourth edition: Qumran and the New Testament, which combines material from xxx-xxxii of the fourth edition with fresh discussions; and Qumran's Greatest Novelty, which includes information from $x x x i i i-x x x v$ of the fourth edition. However, the introduction is virtually identical to that of edition 4 (1995).

Included in the fifth edition are a subject index, scroll catalogue organised by cave, manuscript index, and bibliography. 


\subsubsection{Macro-structure}

The fifth edition and its revision contain eight sections: The Rules; Hymns and Poems; Calendars, Liturgies and Prayers; Apocalyptic Works; Wisdom Literature; Bible Interpretation; Biblically based Apocryphal Works; and Miscellanea. Up to the fourth edition, the Qumran texts are divided into four sections: The Rules; Hymns and Poems; Wisdom Literature; Bible Interpretation; and Miscellanea. The new sections contain most of the new translations. For instance, more than half of the section, "Biblically based Apocryphal Works" is new. The section "Miscellanea" includes seven new texts alongside only one text from the fourth edition (3Q15). In several instances texts have been shifted to other sections; for example, a Messianic Apocalypse (4Q521) has been moved from "Hymns, Liturgies and Wisdom Poetry" to "Apocalyptic Works", while Curses of Melkiresha (4Q280) is listed under "Rules" in the fourth edition but under "Calendars, Liturgies and Prayers" in the fifth. Some texts have been both shifted to another section and renamed (for example, the "Curses of Satan and his Lot" [4Q286-87] are renamed, "Curses of Belial").

The headings and introductions to the Qumran texts have also been updated in the fifth edition. Introductions contain, of course, updated bibliography (e.g., editions in the Princeton project directed by J.H. Charlesworth). Vermes also occasionally lists other fragments even when the translation remains unchanged from the fourth edition. On some occasions, he revises translations based on the additional texts that he lists. For example, in the fourth edition, only $1 Q S$ is listed, while in the fifth edition, he includes under "Community Rule" 1QS, 4Q255-64, 4Q280, 286-87, 4Q502, and 5Q11, 13 (apart from 4Q258 and 259), which he translates separately in both editions. These additional texts are the basis for Vermes' reconstructions of 1QS. Thus, for example, 1QS begins in the fourth edition, "[The Master shall teach the sai]nts to live [according to] the Book of the Community Rule..." In the fifth edition, the basis of Vermes' text-critical judgment is made explicit: "[The Master shall teach the sai]nts to live(?) \{according to the Book\} (4Q255, 257) of the Community [Ru]le..." Similarly, Vermes includes in a footnote (p. 127 n.1) to the first line of CD the addition in 4Q268 of the words, "to me" to "Listen now ..." This tendency to be more explicit is evident as well in the War Scroll (1QM), where Vermes, in the fifth edition, but not the fourth, adds references to texts used in his reconstruction (e.g., 4Q491 in col. 14). The most notable modification of the "Thanksgiving Hymns" is that they are reorganised to follow the reconstruction of E. Puech rather than that of E.L. Sukenik. The Damascus Document has undergone extensive revision. While in the fourth edition, manuscripts from Cave 4 were subdivided into three categories, the inclusion of CD Cave 4 manuscripts has led Vermes to subdivide the manuscripts into seven categories. He has also seriously revised his treatment of MMT (4Q394-99). The fourth edition included only the peroration (4Q399), while the fifth edition includes trans- 
lations of 4 Q394-99, as well as an enlarged introduction. The translation of the Genesis Apocrypha is expanded in the fifth edition, thanks to a preliminary transcription of unpublished material produced with infrared technology.

Vermes' translations continue to be eminently readable in print. To attain this lofty literary excellence, he had to sacrifice line numbering as well as technical detail. However, since the fourth edition (1994) Vermes had aided the reader by indicating every fifth line in the margin of his translation. The headings and introductions (including the bibliography) to the Qumran texts have also been updated.

As in earlier editions, it is often difficult to determine what Vermes is actually translating. For example the reader is provided with no information to determine which of numerous fragments of manuscripts is represented by the translation. For example, from the header on p. 472 (Commentary on Micah [1Q14, 4Q168]) the reader would expect text from both 1Q14 and 4Q168. There is no indication that only 1Q14 is translated. In the table of contents twenty-five Greek manuscripts (4Q119-22, 126-27, 7Q1-19) are mentioned, not a scrap of which is actually translated.

Vermes has also not kept up with advancing scholarship on textual reconstruction. He has left unchanged from the 1987 third edition his rendering of the Temple Scroll column 23, despite the discovery of a manuscript join and a second copy of the Temple Scroll that together have added a paragraph to the text (see Wise 1988; Wacholder \& Abegg 1991). Likewise, he has left unchanged since 1987 his version of 4Q503, relying entirely on the editio princeps for the manuscript reconstruction, despite Joseph Baumgarten's having shown that one must arrange the fragments differently (1985-87).

\subsection{Florentino García Martínez's The Dead Sea Scrolls Translated. The Qumran Texts in English $(1994,1996)$}

\subsubsection{Preliminary data}

This translation of the Hebrew, Aramaic, and Greek manuscripts originates from the Qumrân Institute at the University of Groningen, the Netherlands, and offers the reader, without any knowledge of the original languages of the manuscripts, a translation of the non-biblical manuscripts found in the 11 caves and around Khirbet Qumran. This comprehensive translation was prepared from Florentino García Martínez's Spanish version by Dr. W.G.E. Watson (Department of Religious Studies, The University Newcastle upon Tyne, UK) in close collaboration with him. Watson made changes at the request of García Martínez rendered necessary by his checking the originals 
once more. García Martínez's desire was a translation as literal, as neutral, and as close to the Hebrew and Aramaic text as possible, even if the outcome lacks both finesse and fluency (p.xxv). It is only where the texts were obviously poetic that García Martínez allowed himself some freedom, such as occasionally omitting the ubiquitous conjunction or using synonyms. In the preface it is stated that between the publication of the first Spanish edition of Textos de Qumrán in November 1992 and the appearance of this English translation, four works were published to account for the obvious differences which this English translation displays in respect of the first Spanish edition, namely Tov (1993); Wacholder \& Abegg (1991 and 1992); Eisenman and Wise (1992); and Beyer (1994).

Like the Spanish edition, this English translation omits all kinds of notes or explanations, since everything required to understand these difficult texts will be included in an Introduction to the literature from Qumran, a forthcoming companion volume of this book.

Concerning the second edition, it is stated that due to the short time elapsed between the first publication of this book and the need arising for a reprint, a thorough revision of the work was made impossible. Changes are limited to correct the most obvious typographical errors and to add references to the new numbers given to some of the 4QDamascus Document manuscripts. No attempt has been made to incorporate fragments published in 1995 in the Discoveries in the Judaean Desert Series or in preliminary publications (thus, the second edition in fact added no new texts, and so the contents represent those of the first). Only the last section of the book, the "List of the manuscripts from Qumran", has been brought up to date fully, considering all new publications.

This translation claims to offer the reader a translation of the 270 most important manuscripts from Qumran. In other words, it is a virtually complete translation of the non-biblical manuscripts found there. (On the title page, it is typified as the authoritative new translation of the Dead Sea Scrolls, complete in one volume.) However, a large part of the manuscripts comprises remains so fragmentary that to translate them would be of absolutely no value to the reader. This translation is then not a translation of all the non-biblical manuscripts recovered from the vicinity of Qumran, but it claims to include all the most important ones. The total number of manuscripts recovered comes to about 800 . Of these manuscripts, 225 are copies of various biblical books, and a translation of them would be out of place in this volume. Of another 300 manuscripts, so little of the text has been preserved that translating them would make no sense. These are minute remains of unidentified manuscripts and of fragments, which mostly contain traces of a few complete words. Of the other $\mathbf{3 0 0}$ or so manuscripts, the 200 longest and most important have been 
included in this translation. (At that stage, it was the most complete translation; the third edition of the English translation by Geza Vermes, published in 1987, contains only the better preserved sections of 62 manuscripts). Although the number of the remaining manuscripts, between 100 and 150, might still seem large, the amount of text, which can be recovered from them, is comparatively small, since all of them contain very small fragments. A rough calculation shows that the contents of all of them could not be expected to be 5 percent of the text of the manuscripts included here. To give a concrete example: the five copies of the Hymns of Cave 4 (4Q427-431), which have not been included in the present translation, together constitute a shorter text than a single one of the 25 columns of $1 \mathrm{QHa}$.

García Martínez translated different surviving copies of a single work with special attention to minute variations between them, so as not to prejudge whether they are actual copies of the same text, different editions, re-use of the same material in another context, etc. He has only attempted to restore parallel passages when the layout of a text so restored, in the particular script of each manuscript, seems to allow this.

The presentation of the translations attempts to reflect the actual state of preservation of the various manuscripts. Hence the indications of spaces left blank, interlinear insertions, corrections or erasure of certain words, etc. Accordingly, there are sparse restorations. Only when the presence of parallel passages, the repetitiousness of the formulas used or other equally persuasive factors permit, has García Martínez allowed himself to restore (in square brackets) the text actually preserved. In any case, these restorations are no more than suggestions and are intended simply to make the text easier to read.

All the translations have been made with photographs of the originals in front of García Martínez. In the case of manuscripts already published, the editio princeps or the preliminary edition, as well as later translations and studies, have been taken into consideration. However, this does not imply that the reading or interpretation adopted here is always that proposed by editors or other scholars. In the case of the texts from Caves 4 and 11, here translated for the first time, the translation is based on García Martínez's own transcription of these texts.

An introductory chapter provides an overview of the discoveries, text, controversies, and the author's views about the group, its history, and its library. García Martínez's assumptions on the identity and origins of the Qumran community can be summarised from these parts as follows:

1. The scrolls belonged to a group of people with their central community in the ruins of Qumran, as has been adequately established by archaeological excavations. They have also provided the definitive latest date when 
the manuscripts were stored in the caves: the year 68 of the $1^{\text {st }}$ century. The implication is that all the manuscripts were copied before this date.

2. The Qumran community cannot possibly be identified with the Zealots or the Jewish-Christian community since neither the chronological outline nor the resulting profile fits. It has been determined that of the three best-known groups of Judaism in the mid-second century BCE until the time of the destruction of Qumran in 68 CE (the Sadducees, the Pharisees and the Essenes), the group most closely resembling the Qumran group is indeed the Essenes. Furthermore, the similarities between that which classical sources tell us about the Essenes and the information provided by the manuscripts are so close, that it would be impossible to deny a strong connection between the Qumran group and the Essenes. This connection is usually understood as a simple equation between the elements in question: Essenes = Qumran group. However, this equation is impossible. The genuine parallels indeed require a connection between the two entities, but there are differences between them of such a nature as to preclude them from being identical. The best way to make sense of the undeniable connection that existed between the Essene movement and the Qumran community is to accept that the Qumran community arose specifically because of a rift caused within the Essene movement to which the founder members belonged. This proposal comprises one of the essential elements of the "Groningen Hypothesis", which best explains the known facts in their entirety, both in respect of the Essenes and in respect of the Qumran community.

3. The new discoveries, in providing us with part of pre-Christian Jewish literature in Hebrew and Aramaic, promised to close the existing gap between Biblical and Mishnaic Hebrew and between the Aramaic of Elephantine and Targumic Aramaic.

4. In addition, and for the first time, we would own a whole range of religious compositions, which reached us directly, absolutely devoid of any later interference. Since the texts were preserved on the fringes of conventional life, they reached us free from the restraints of censorship. Largely, Jewish censorship suppressed religious literature, which did not comply with rabbinic orthodoxy; Christian censorship would have assimilated some of these works, but after modifying them for their own purposes.

5. Since the new manuscripts stem from Palestine and are earlier in date than the destruction of Jerusalem, study of them promises to resolve the complex history of the country at this critical time. In addition, since this time is a period of development both for Christianity and for Rabbinic Judaism, the new texts will make the background, origins, and development of these two important religions intelligible. 
6. Among the works, a significant number can be classified as representing sectarian theology and customs; therefore, we can describe this library as a sectarian library. All the manuscripts found in the caves belong to the same library. It is obvious that not all the manuscripts found in the caves originate from Qumran. Due to the separatist nature of the community, the mere fact of belonging to the group library convinces us that the community considered them to be in agreement with its principles, with its halakhah and even with its tenets. The spectrum of ideas reflected in these works seems to have caused no more problems than the variety of ideas to be found in the books of the Bible. This allows us to conclude that all the works, which were retrieved, belong to the longer history of the sect. Otherwise they were kept because the sect saw in them confirmation of their prehistory, of the religious movements which influenced their development and nourished their origins, forming part of the legacy within which, as in the various Biblical books, the sect identifies itself.

\subsubsection{Macro-structure}

Each work is provided with a title, which makes identification much easier to remember than the serial number of the official publication. The editors have provided a large number of the manuscripts already published with titles of this kind. In order to avoid confusion, the titles given by the editors have been retained, even when they are clearly unsuitable. In most cases the title assigned describes in one way or another the contents of the manuscript.

The translations are arranged in the following way: The first chapter contains the main rules of the sect. These documents provide us with the most information concerning the organisation, way of life, customs, and thought of the community or communities for which they were intended. Chapter 2 is a collection of texts, which are equally normative, the halakhic texts, which show us in practice the characteristic application of Old Testament law current within the group. The third chapter is an assortment of compositions, though all of them share the same theme dominant in the concerns of the Qumran community: the exploration of the truths of "the last days". Chapter 4 collects the exegetical output of the community, compositions directly concerned with showing us how the Biblical text was interpreted, translated, and even altered. Chapter 5 assembles a long series of "Para-biblical literature". Some of these are compositions parallel to the Biblical text, approximating the original text in different degrees; others represent independent traditions developed around Biblical personages. Some others again reveal to us literary creations of the same type as the Biblical narratives, which by chance were not included in the Bible, although a few of them, such as the Book of Jubilees, seem to have enjoyed truly Biblical authority within the community. Chapter 6 gathers poetic 
compositions, which may or may not have been used in the liturgy, apocryphal psalms, wisdom poems, etc. Chapter 7 contains those works probably intended for liturgical use or which are remains of rituals. In Chapter 8, astronomical compositions, calendars and horoscopes found in the caves, are represented - all works of fundamental religious importance for the Qumran community. The ninth chapter contains a single document: the Copper Scroll, a unique text, the meaning of which continues to be mystifying. The translations give the column and line numbers and include full renderings of multiple copies of texts.

Following on from the edition with transcribed text and Dutch translation by García Martínez and A.S. van der Woude, García Martínez has now teamed up with Eibert J.C. Tigchelaar to produce The Dead Sea Scrolls Study Edition in two volumes. All manuscripts are arranged according to Q-numbers, making it very easy to locate any given manuscript, provided the reader knows the $Q$ number. The English translation of García Martínez is the basis for the translations in this volume, though they have all been rechecked. However, the English plods along in the same monotonous dull tone, even where the source text possess some beauty. Now the Semitic text is also included to make this the handiest edition available to those who read English. The degree of reconstruction provided differs from text to text. In some cases, García Martínez and Tigchelaar have accepted virtually every suggestion the original editor has made. In other instances, no reconstruction appears at all. These are not situations where the initial editor has failed to make a case; rather, it evidently matters who made the suggestion (e.g., 4Q563).

\subsection{Michael Wise, Martin Abegg, and Edward Cook's The Dead Sea Scrolls. A New Translation (1996)}

\subsubsection{Preliminary data}

The title page states that it is a comprehensive translation of the controversial ancient scrolls, with material never published or translated before now, and including the most recently released texts. The translation was published on the eve of the fiftieth anniversary of the discovery of the Dead Sea Scrolls and is intended for the non-specialist (p. 4). They testify to the literary culture that gave birth to the foundational religious documents of Judaism and Christianity. The translators are Evangelical Christian Scholars in North American institutions. The aim was to present flowing, idiomatic translations, as far as that has been possible given the frequently fragmentary materials. They qualify their translation by stating that there is no single translation equivalent for many 
words, not to speak of phrases or entire texts. Some words have many possible rough equivalents and by their translation effort may violate or betray the original. The translation is viewed by them as more of a beginning of research on the scrolls than it is a completion, although they hope that most of it will stand the test of time and become foundation stones for subsequent generations of students.

A "Prolegomena" contains an introduction, covering the discovery and publications, the nature of writing activity, scripts and languages as well as the contents of the scrolls. The sections on the origin of the scrolls, the Standard Model, the site of Qumran, as well as a new proposal for the origin of the scrolls and value of the scrolls for today reveal the assumptions of the translators. A time chart and a section on how to read a Dead Sea Scroll are included. The translators' assumptions can be summarised as follows:

1. The Standard Model of Qumran Origins has become less convincing, as additional evidence has come forth from archaeology and the texts (p. 26).

2. The archaeology of Qumran cannot support the Standard Model. One can no longer reasonably argue for a "strong" connection between the site and the scrolls, though the two may have a "weak" connection; that is, though the sect may have used the site, it cannot possibly have been their main location (p. 24).

3. The Essene hypothesis of the Standard Model is in itself vulnerable and is crumbling because of facts coming from the new texts (p. 25).

4. The evidence suggests that the scroll group resembled the Sadducees in some ways and the Essenes in others. Yet there are major obstacles in the way of identifying the group straightforwardly as one or the other. Evidence implies that the sect (whoever they were) took sides in the interJewish political conflicts of the first century BCE. They favoured Alexander over his opponents, the Pharisees, and favoured Sadducean law over its opponents, the Pharisees. Other evidence seems to point to an era when the tide was turning away from Alexander's partisans in favour of the old enemies, the Pharisees, probably during the reign of Salome Alexandra, the widow of Alexander.

5. Various carrier groups (groups who adopt another's ideology) may well have been reading the scrolls in the following century.

\subsubsection{Macro-structure}

Each text is provided with a short introduction. The various translations are presented in 131 sections. The sequence follows the official numbering. 


\section{THE MICRO-STRUCTURE ANALYSIS OF THREE ENGLISH TRANSLATIONS OF THE DEAD SEA SCROLLS}

\subsection{Lexical diversity of the translations}

In the first instance, the type-token relation analysis of six Qumran texts of each of the three translations is done by means of WordSmith Tools. This is a very basic type of calculation in WordSmith Tools to measure the lexical variation of diversity in the corpus. The type-token relation of the words reveals the nature of the translation process. Type refers to the number of different words in a text; token refers to the total number of running words in the text. The higher the ratio, the more varied the vocabulary. This implies that there is very little repetition. The results of this analysis are reflected in Table 1.

\begin{tabular}{|l|c|c|c|}
\hline \multicolumn{1}{|c|}{ 1QS } & Vermes & García Martínez & Wise, Abegg \& Cook \\
\hline Tokens & 9051 & 9350 & 10601 \\
\hline Types & 1274 & 1443 & 1773 \\
\hline Type/Token ratio & 14.08 & 15.43 & 16.72 \\
\hline Standardised type-token ratio & 30.85 & 32.99 & 36.92 \\
\hline
\end{tabular}

\begin{tabular}{|l|c|c|c|}
\hline \multicolumn{1}{|c|}{ CD } & Vermes & García Martínez & Wise, Abegg \& Cook \\
\hline Tokens & 8713 & 9357 & 9313 \\
\hline Types & 1501 & 1583 & 1773 \\
\hline Type/Token ratio & 17.23 & 16.92 & 19.04 \\
\hline Standardised type-token ratio & 35.79 & 36.15 & 38.25 \\
\hline
\end{tabular}

\begin{tabular}{|l|c|c|c|}
\hline \multicolumn{1}{|c|}{ 1QSa } & Vermes & García Martínez & Wise, Abegg \& Cook \\
\hline Tokens & 1865 & 1627 & 2133 \\
\hline Types & 420 & 447 & 574 \\
\hline Type/Token ratio & 22.52 & 27.47 & 26.91 \\
\hline Standardised type-token ratio & 33.50 & 37.30 & 39.70 \\
\hline
\end{tabular}




\begin{tabular}{|l|c|c|c|}
\hline \multicolumn{1}{|c|}{ 1QpHab } & Vermes & García Martínez & Wise, Abegg \& Cook \\
\hline Tokens & 3983 & 3307 & 4761 \\
\hline Types & 785 & 832 & 1003 \\
\hline Type/Token ratio & 19.71 & 25.16 & 21.07 \\
\hline Standardised type-token ratio & 33.10 & 39.70 & 37.07 \\
\hline
\end{tabular}

\begin{tabular}{|l|c|c|c|}
\hline \multicolumn{1}{|c|}{ 1QM } & Vermes & García Martínez & Wise, Abegg \& Cook \\
\hline Tokens & 9567 & 10603 & 10617 \\
\hline Types & 1371 & 1413 & 1550 \\
\hline Type/Token ratio & 14.33 & 13.13 & 14.60 \\
\hline Standardised type-token ratio & 31.86 & 31.46 & 33.21 \\
\hline
\end{tabular}

\begin{tabular}{|l|c|c|c|}
\hline \multicolumn{1}{|c|}{$1 \mathrm{QH}$} & Vermes & García Martínez & Wise, Abegg \& Cook \\
\hline Tokens & 14750 & 20327 & 15677 \\
\hline Types & 1748 & 2106 & 2224 \\
\hline Type/Token ratio & 11.85 & 10.36 & 14.19 \\
\hline Standardised type-token ratio & 31.59 & 31.39 & 36.65 \\
\hline
\end{tabular}

Table 1: Type-token relation analysis by means of WordSmith Tools The following inferences may be drawn from the data in Table 1:

1. When compared to the translations of Vermes and García Martínez, the translation of 1QS, 1QSa, 1QpHab and 1QM by Wise, Abegg \& Cook have in each case the highest amount of tokens. It seems that Wise, Abegg \& Cook make use of explicitation in their translation. Vermes' translations of 1QS, CD, 1QM and 1QH have the least number of tokens when compared to García Martínez and Wise, Abegg \& Cook. It seems that Vermes' translations show simplification of the source text. García Martínez uses more tokens as Vermes in the translations of $1 \mathrm{QS}, \mathrm{CD}, 1 \mathrm{QM},(1 \mathrm{QH})$ and less than Wise Abegg \& Cook in 1QS, 1QSa, 1QpHab and 1 QM. García Martínez reflects the Hebrew source text literally and shows the tendency of normalisation. By using more words/tokens, it seems that Wise, Abegg \& Cook employ explicitation, i.e. an overall tendency to spell things out rather than leave them implicit in translation (Baker 1996:180). The implication is that translations are usually longer than their source texts. As a translation for a dual audience of scholars and educated lay people, the translations 
of Vermes have considerably less tokens than any of the other translations. Although explicitation is to be expected, it seems that simplification (in this case the omission and avoidance of lexical repetition) has been employed as a translation strategy. García Martínez's desire was a translation as literal, as neutral and as close to the Hebrew and Aramaic text as possible. It was only in poetry where Watson, the translator, was allowed to some freedom. This fact is borne out by the statistics: The translation of 1QH by García Martínez shows 20327 tokens, whereas that of Wise, Abegg \& Cook has 15677 and the translation of Vermes 14750 . This fact may also be supported by the statistics of $1 \mathrm{QpHab}$ and $1 \mathrm{QSa}$, where considerable reconstruction is done in the translation of Vermes. The lower number of tokens in the translation of CD by Wise Abegg \& Cook is due to the use of a consolidated text of Manuscript A and B.

2) The translations of Wise, Abegg \& Cook have the highest number of types in all six translations, which were investigated, due to explicitation. All translations of García Martínez have the second highest rate of types. The García Martínez translation seems to have attempted to translate each Hebrew word with a similar word in the target language and reflects the source text closely. All the translations of Vermes utilise the lowest number of types respectively. As result of simplification, it is expected that the number of types in the translation of Vermes will be lower, i.e. certain types are used for more than one source text word.

3) Except for the translation of $1 \mathrm{QpHab}$, the type-token ratio is the highest in the translations of Wise, Abegg \& Cook, i.e. this translation has the greatest number of type diversifications per 1000 words. This supports the view that Wise, Abegg \& Cook use explicitation. Except for $1 \mathrm{QH}$ and $1 \mathrm{QM}$, it is the lowest in the translations of Vermes (i.e. the least type diversification per 1000 words). As stated above, the García Martínez translation seems to have attempted a translation of each Hebrew word with a similar word in the target language and reflects the source text closely. In cases with a low type-token relation, the same English word is used for various Hebrew words, e.g. the translations of Vermes, due to simplification.

An example from The Rule of the Community (1QS1.1-3) justifies the conclusions concerning translators' style. 
Hebrew source text: 24 words

Vermes: 49 words (Simplification)

I [The Master shall teach the saints to live(?) \{according to the Book\} $(4 \mathrm{Q} 255,257)$ of the Community [Rul]e, that they may seek God with a whole heart and soul, and do what is good and right before Him as He commanded by the hand of Moses and all His servants the Prophets...

García Martínez: 56 words (Normalisation)

Col. i 1 For [the Instructor] ... for his life, [book of the Rul]e of the Community: in order to 2 seek God [with all (one's) heart and with all (one's) soul; in order] to do what is good and just in his presence, as 3 he commanded by means of the hand of Moses and by the hand of all his servants the Prophets...

Wise, Abegg \& Cook: 63 words (Explicitation)

Col. $1 \mathrm{~A}$ text belonging to [the Instructor who is to teach the Ho]ly Ones how to live according to the book of the Yahad's Rule. He is to teach them to seek God with all their heart and with all their soul, to do that which is good and upright before Him, just as He commanded through Moses and all His servants the prophets.

\subsection{The translation of self-designation}

In the second instance, I used Wordsmith Tools to compare wordlists of the translations of the three translations of 1QS and identify words that occur more frequently, less frequently or not at all in one and two of the three lists. The KeyWords Tool was used to compare the words in 1QS of the English translations of the Dead Sea Scrolls with the reference set of words taken from all the translations in the corpus. Any word that is found to be outstanding in its frequency in the particular translation is considered a "keyword". These keywords were then compared to the wordlists obtained for each of the other translations by means of the WordList Tool to determine their frequency in the various translations of $1 \mathrm{QS}$. Some keywords of each translation were identified, as well as their distribution/occurrence in 1QS of the English translations of the Dead Sea Scrolls. The lack of a keyword in a particular translation implies that the translator had to find another strategy to deal with the concept represented by the keyword. This leads to explicitation or simplification (by omission). The consolidated list of the keyword analysis and their frequency in the various English translations of $1 \mathrm{QS}$ produced the data as in Table 2 below. 


\begin{tabular}{|l|c|c|c|}
\hline \multicolumn{1}{|c|}{ 1QS } & Vermes & García Martínez & Wise, Abegg \& Cook \\
\hline Yahad & 0 & 0 & 50 \\
\hline community & 56 & 57 & 2 \\
\hline council & 20 & 21 & 33 \\
\hline membership & 0 & 0 & 21 \\
\hline society & 0 & 0 & 34 \\
\hline covenant & 31 & 33 & 2 \\
\hline assembly & 9 & 4 & 18 \\
\hline
\end{tabular}

Table 2: Consolidated word list and keyword analysis by means of WordSmith Tools

Wise, Abegg \& Cook use the association's most common self-designation, namely Yahad and avoid various possible English semi-equivalents. It is clear that the choice of vocabulary is shaped by the assumptions of a particular translator. In 4Q246, Vermes translates מרינה as "province", whereas García Martínez has "city" (which is anachronistic), while Wise, Abegg \& Cook render it freely by "nation".

The Concord Tool in WordSmith was used to substantiate the context of each usage, for example, 1QS 3.12:

Hebrew ST: (5 words.)

Vermes: It shall be to him a Covenant of the everlasting Community. (11 words.)

García Martínez: And for him it will be a covenant of an everlasting Community. (12 words.)

Wise, Abegg \& Cook: And then only shall he be a party to the Covenant of the eternal Yahad. (15 words.)

The following list illustrates a selection of words concerning "community" from the wordlists of each translation. 


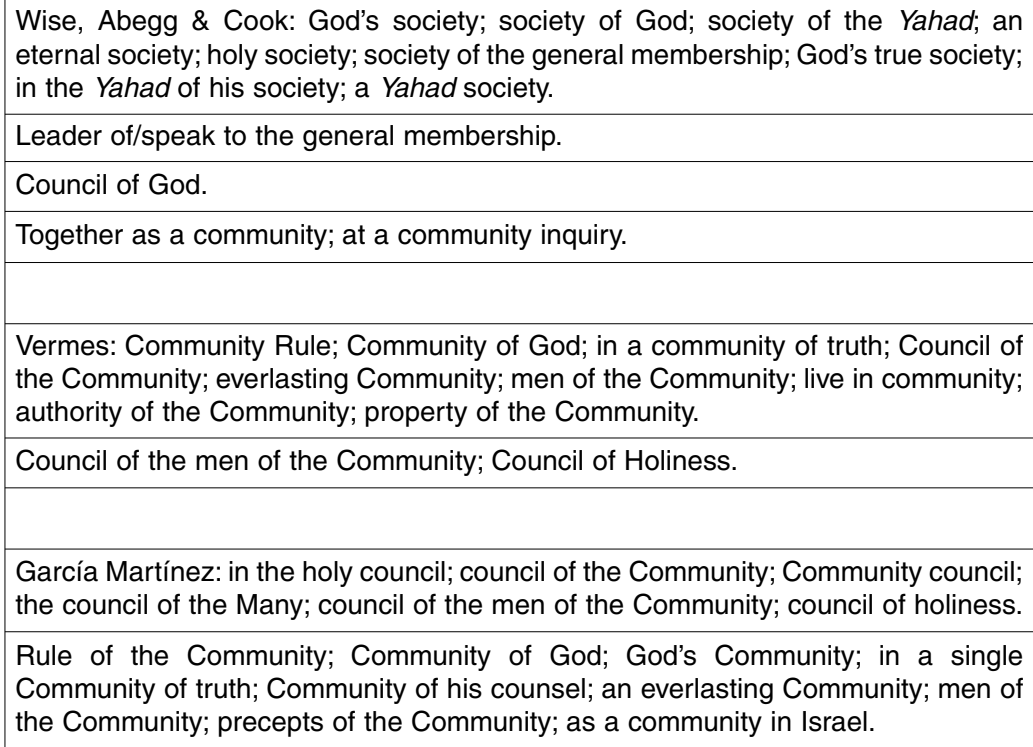

\subsection{The use of inclusive language}

Pronouns, conjunctions, etc. are generally not considered to be "keywords" and their distribution is therefore not presented in Table 2. However, their distribution in the various English translations of the Dead Sea Scroll varies considerably and may be significant in the representation of the translator styles in the various English translations of 1QS. The particular wordlists compiled by the WordList Tool were compared with each other and the consolidated list of the distribution of a selection of pronouns, conjunctions, etc. in each translation is represented in Table 3. 


\begin{tabular}{|l|c|c|c|}
\hline \multicolumn{1}{|c|}{ 1QS } & Vermes & García Martínez & Wise, Abegg \& Cook \\
\hline He & 144 & 146 & 140 \\
\hline His & 184 & 225 & 160 \\
\hline Him & 51 & 47 & 39 \\
\hline Her & 0 & 0 & 55 \\
\hline Their & 58 & 69 & 25 \\
\hline Them & 37 & 31 & 63 \\
\hline They & 64 & 64 & 0 \\
\hline
\end{tabular}

Table 3: Consolidated word list analysis of elements not considered as keywords by means of WordSmith Tools

There is no inclusive language use by any of the translators. A strategy for inclusive language use is to change the third person singular to the third person plural. The results of WordSmith Tools do not support such a change. This language usage is also supported by the keywords in Table 4. The term "sons" is avoided by Wise, Abegg \& Cook where the translation equivalent "membership" or "comrades" is used.

\begin{tabular}{|l|c|c|c|}
\hline \multicolumn{1}{|c|}{ 1QS } & Vermes & García Martínez & Wise, Abegg \& Cook \\
\hline human & 1 & 2 & 5 \\
\hline humanity & 0 & 0 & 2 \\
\hline humankind & 0 & 2 & 40 \\
\hline man & 43 & 24 & 0 \\
\hline mankind & 3 & 1 & 2 \\
\hline sons & 15 & 22 & 0 \\
\hline woman & 1 & 1 & 8 \\
\hline comrades & 0 & 0 & 2 \\
\hline
\end{tabular}

Table 4: Consolidated word list and keyword analysis by means of WordSmith Tools 


\begin{tabular}{|l|c|c|c|}
\hline \multicolumn{1}{|c|}{ 1QS } & Vermes & García Martínez & Wise, Abegg \& Cook \\
\hline the & 591 & 676 & 613 \\
\hline of & 453 & 485 & 394 \\
\hline and & 306 & 335 & 225 \\
\hline
\end{tabular}

Table 5: Consolidated word list analysis of elements not considered as keywords by means of WordSmith Tools (Cont.)

The data in Table 5 support the findings of Table 1 that the translation of García Martínez demonstrates a tendency towards conservatism/conventionalisation or normalisation. García Martínez's desire was a translation as literal, as neutral and as close to the Hebrew and Aramaic text as possible. It implies that the definite article, the construct state and conjunctions of the source text will be honoured. This explains why García Martínez uses more tokens in this regard.

\subsection{Rehabilitation of the Jewish source culture}

For some forty-five years, the scholars publishing and interpreting the scrolls have focused almost single-mindedly on the scrolls' significance for the understanding of early Christianity. It was only in the early 1990s that scholars claimed that by understanding what the scrolls can teach us about the history of Judaism we could effectively learn what they have to teach us about the history of Christianity, a religious tradition that came into being only after these texts were composed and copied. As indicated in Table 6 Vermes $(1997,2004)$ rehabilitated the Jewish source culture by using target text items clearly used in Jewish religious contexts.

\begin{tabular}{|l|l|l|}
\hline \multicolumn{1}{|c|}{ 1QS } & 1962, 1975, 1987, 1994 & \multicolumn{1}{c|}{1997,2004} \\
\hline $1.19,23 ; 2.5,19 ; 10.21$ & Satan & Belial \\
\hline $3.19,20,22 ; 4.18,22(2 x)$ & falsehood & injustice \\
\hline $5.13 ; 5.14,18$ & saints & men of holiness \\
\hline $6.3,8 ; 7.1$ & pray(ing) & bless(ing) \\
\hline 8.12 & Authority & foundation \\
\hline $8.14 ; 11.7$ & ungodly (men/flesh) & unjust \\
\hline 9.21 & ungodliness & injustice \\
\hline
\end{tabular}

Table 6: Rehabilitation of the source culture in the 1QS translation of Vermes 1962 and 1997 


\section{CONCLUSION}

The issue of stylistic variation boils down to linguistically inscribed preference in the choice and construction of discourses in the translated texts, i.e. a case of identifying the norms governing the patterning of translational behaviour within a given socio-cultural milieu.

The analysis of the preliminary data and macro-structure of the three English translations of the Dead Sea Scrolls are summarised as follows:

1) Vermes' introductory chapters cover four topics: the history of the discoveries (this was not present in the earlier editions), the Community, its history, and its religious ideas. Only the first three of these are covered in García Martínez, while Wise, Abegg \& Cook's introductory section is of a different character. Policy over introductions to the texts themselves varies considerably: García Martínez is rather brief, and he limits his introductory material just to the beginning of each larger grouping of texts, whereas both Vermes and Wise, Abegg \& Cook provide each text with a short introduction; Vermes is generally more informative, judicious, and helpful.

2) The texts themselves are organised in different ways in the three collections: Whereas Wise, Abegg \& Cook follow the sequence of the official numbering, both Vermes and García Martínez classify the texts into different genres, and a comparison of their two tables of contents will at once indicate how difficult it is to do this in a generally agreed way. To cite but two instances, the War Scroll features in Vermes under "Rules", but in García Martínez under "Literature with eschatological content", and, whereas Vermes has a section of "Wisdom texts", Garcia Martinez incorporates these under the more general heading of "Poetic texts".

3) All three of the collections contain somewhat different materials:

a) Only Vermes and Wise, Abegg \& Cook provide the important 4Q448, mentioning "King Jonathan". All three collections include the Geniza text of the Damascus Document, whereas for the Testament of Levi the Geniza manuscript is only used by Wise, Abegg \& Cook (but in a rather confusing way). Where several manuscripts attest a single work, as for example with Jubilees, García Martínez provides by far the fullest coverage. Vermes is likewise rather more sparing than García Martínez and Wise, Abegg \& Cook in providing translations of very fragmentary texts. All three collections adopt the new numbering of the Hodayot, based on Puech's reordering of the column fragments. Vermes's fourth edition still had the old numbering.

b) Only Vermes gives, at the end of the volume, translations of two ostraca found recently on the site of Qumran. The first of these is 
potentially of great significance, since, according to the reading of Cross and Eshel (1997:17-28), it includes a reference to the yahad. If this were correct, it would be the sole piece of evidence specifically providing a link between the sectarian texts of the caves and the site below of Qumran. Unfortunately, the subsequent re-examination of the ostracon by Yardeni (1997:233-37) resulted in a completely different reading at this point, leaving no reference to the yahad at all. No update of this development is mentioned in the 2004 edition.

c) Vermes does not include $4 \mathrm{Q} 559$ and $4 \mathrm{Q} 560$, both of which contain a substantial amount of interesting material. It does not include the fullest possible versions of many texts (for example, The Testament of Amram, 4Q317).

The conclusions that follow from the analysis of the micro-structure of six translated texts of the three English translations of the Dead Sea Scrolls are:

1) Vermes' translation demonstrates the tendency to simplify the language used in translation, in other words he (and Pam) attempt to make things easier for the reader (but not necessarily more explicit). If the target text has a lower information load than the source text, it is because ambiguous information in the original has been disambiguated (made simpler) in the translation process (Toury 1995:270). Delabastita (1993:35) talks of the pruning or trimming of the original. Omitting aspects of the original text is the most direct way of simplifying a translation.

2) The translation of García Martínez demonstrates a tendency towards conservatism/conventionalisation or normalisation. The trend is towards general textual conventionality as opposed to textual creativity as in the case of the translation of Wise, Abegg \& Cook and Vermes. Conservatism is most evident in the use of typical grammatical structures, punctuation and collocational patterns. It exaggerates features of the target language and conforms to its typical patterns.

3) In the translation by Wise, Abegg \& Cook there is an overall tendency to spell things out rather than leave them implicit. The evidence for this tendency is found in the fact that a translation is usually longer than their originals. Lexically the tendency to make things explicit in translation may be expressed through the use or overuse of explanatory vocabulary that are added to the target text. According to Delabastita (1993:36), addition as translation strategy (i.e. the insertion of information in the translation that is absent in the original text) can partly be ascribed to translators' understandable concern for clarity and coherence, which prompts them to disentangle or explain complicated passages, provide missing links, lay bare unspoken assumptions i.e. implicit meanings, and generally give the text a fuller wording (i.e. elaborate on the original.) 


\section{BIBLIOGRAPHY}

BAKER, M.

1996. Corpus-based translation studies: The challenges that lie ahead. In: $\mathrm{H}$. Somers (ed.), Terminology, LSP and translation (Amsterdam: John Benjamins), pp. 175-186.

2004. The treatment of variation in corpus-based translation studies. Language Matters 35(1):28-38.

BAUMGARTEN, J.

1985-87. 4Q503 and the Lunar Calendar. Revue de Qumran 12:105-36.

BEYER, K.

1994. Die aramäischen Texte vom Toten Meer. Ergänzungsband. Göttingen: Vandenhoeck \& Ruprecht.

BURNETT, S.

1999. A corpus-based study of translational English. Unpublished M.Sc. dissertation. Manchester: UMIST.

Cross, F.M. \& Eshel, E.

1997. Two Qumran ostraca. IEJ 47:17-28.

DELABASTITA, D.

1993. There's a double tongue: An investigation into the translation of Shakespeare's wordplay, with special reference to 'Hamlet'. Rodopi: Amsterdam.

EISENMAN, R. \& Wise, M.O.

1992. The Dead Sea Scrolls uncovered. Shaftesbury: Element.

García MaRTínez, F. 1996 (1994). The Dead Sea Scrolls translated. The Qumran texts in English. Brill: Leiden.

GASTER, T.

1957. The Scriptures of the Dead Sea Sect in English translation. London: Secker \& Warburg.

KENNY, D.

2000. Lexis and creativity in translation: A corpus-based study. Manchester: St. Jerome.

MUNDAY, J.

2002. Systems in translation. A systemic model for Descriptive Translation Studies. In: T. Hermans (ed.), Cross cultural transgressions. Research models in Translation Studies II. Historical and ideological issues (Manchester: St. Jerome), pp. 76-92.

NAUDÉ, J.A.

2004. Representation of poetry in Afrikaans Bible translations: A corpus-based analysis. Language Matters 35(1):226-247. 
OLOHAN, M. \& BAKER, M.

2000. Reporting that in translated English: Evidence for subconscious processes of explicitation? Across Languages and Cultures 1(2):141-158.

SIDIROPOULOU, M.

2004. Linguistic identities through translation. Amsterdam: Rodopi.

TOURY, G.

1995. Descriptive translation studies and beyond. Philadelphia: John Benjamins.

Tov, E.

1993. The Dead Sea Scrolls on microfiche. A comprehensive facsimile edition of the texts from the Judaean Desert. Leiden: Brill.

Vermes, G.

1995 (1962, 1975, 1987). The Dead Sea scrolls translated. London: Penguin.

1999. Providential accidents. An autobiography. Oxford: Rowman \& Littlefield.

2004 (1997). The complete Dead Sea Scrolls in English. London: Penguin.

Wscholder, B.Z. \& ABEgG, M.

1991. The fragmentary remains of 11 QTorah [Temple Scroll]. Hebrew Union College Annual 62.

1991-1992. A preliminary edition of the unpublished Dead Sea Scrolls. Washington, DC: Biblical Archaeological Society.

WiSE, M.O.

1988. A new manuscript join in the 'Festival of Wood Offering' [Temple Scroll XXIII]. Journal of Near Eastern Studies 47:474-83.

Wise, M., Abegg, M. \& CoOK, E.

1996. The Dead Sea Scrolls. A new translation. London: HarperCollins.

YARDENI, A.

1997. A draft deed on an ostracon from Khirbet Qumran. IEJ 47:233-37.

Keywords

Translation Studies

Stylistic variation

Dead See Scrolls

Vermes

Wise, Abegg \& Cook

García Martínez
Trefwoorde

Vertaalkunde

Stilistiese variasie

Dooie See Rolle

Vermes

Wise, Abegg \& Cook

García Martínez 